\title{
Demonitizaton and its Effects on Digital Payments
}

\author{
Dinesh, T.M. ${ }^{1 *}$ and Kiran Kumar Reddy ${ }^{2}$
}

${ }^{1}$ Department of Agricultural Economics, Prof. Jayashankar Telangana State Agricultural University, Hyderabad, Telangana, India ${ }^{2}$ Department of Agricultural Statistics, Prof. Jayashankar Telangana State Agricultural University, Hyderabad, Telangana, India

*Corresponding author: dineshtm07@gmail.com

\begin{abstract}
Demonetization refers to an economic policy where certain currency units cease to be recognized as a form of legal tender. The Indian government had demonetized bank notes on three times 1946, 1978 and October-2016. In order to evaluate the impact of demonetization on digital payments, data was collected from May-2016 to October-2017 from NPCI web portal. Exploratory data analysis indicated debit card users increased by 414 percent followed by NEFT by 155 and RTGS by 122 percent. The mobile transaction was seen to have highest CAGR of 3.40 percent. A similar trend followed in case of the value of transactions i.e., the highest growth was in a debit card with 205 percent followed by mobile and NEFT by 193 and 178 percent respectively. Overall, the study concluded that there was a significant effect of demonetization on digital payments.
\end{abstract}

Keywords: Demonetization, Growth rate, Cash, Digital payments, Debit card, Mobile banking, etc..

Demonetization refers to an economic policy where a certain currency unit ceases to be recognized or used as a form of legal tender. In other words, a currency unit still loses its legal tender status as a new one comes into circulation. The Indian government had demonetised bank notes on two prior occasions-once in 1946 and then in 1978and in both cases, the goal was to combat tax evasion by "black money" held outside the formal economic system. In 1946, the pre-independence government hoped demonetisation would penalise Indian businesses that were concealing the fortunes amassed supplying the Allies in World War II. In 1978, the government demonetised banknotes of 1000, 5000 and 10,000 rupees, again in the hopes of curbing counterfeit money and black money. And now on 08 November 2016 the Government of India announced the demonetisation of all ₹ 500 and ₹ 1000 banknotes of the Mahatma Gandhi series.

\section{Effects of Demonetization of 2016 on digital industry}

Paytm received more than 25,000 signups.

Razorpay witnessed $150 \%$ spike on the morning after the decision was announced, which by afternoon, shot up to $200 \%$.

Mobikwik saw a 15-fold increase in traffic.

Freecharge reported in $12 X$ jump the average balance.

Shopclues business from smaller town \& cities increase by $15 \%$.

Online food ordering and delivery start-ups are seeing an increase in sales by $40-50 \%$.

Cash crunch among public has become so bad that major e-commerce players have removed the Cash-on-Delivery (CoD) option from their payment gateway.

Many have paused their digital campaigns. And while small grocery and vegetable vendors saw huge dip in sales, grocery e-tailers experienced big surge in direct traffic, sometimes exceeding their operating capacity.

Digital payments are electronic consumer transactions, which include payments for goods and services that are made over the internet, mobile payments at Point-of-Sale (PoS) via smartphone 
applications (apps), and peer-to-peer transfers between private users. Transactions are done through electronic media channels such as direct debit, credit and debit cards, and electronic clearing and payment systems such as Immediate Payment Service (IMPS), National Electronic Funds Transfer (NEFT) and Real Time Gross Settlement (RTGS). Today, credit cards and online payment services are becoming increasingly popular in urban India, paper currency notes are still an essential part of daily life. The sector is experiencing an unprecedented jump in growth since November last year, when the government demonetized high currency bills ( $₹ 500$ and 1000) - which represented 86 percent of India's cash in circulation. By February this year, digital wallet companies had shown a growth of 271 percent for a total value of US $\$ 2.8$ billion (₹ 191 crore).

\section{METHODOLOGY}

This chapter describes the methodology which has been adopted for conducting the research work. The paper is exploratory in nature. The study has been carried out based on the collection of the relevant secondary data. Secondary data collection was based on various sources such as NPCI, RBI.

Exploratory data analysis (EDA) is the first and foremost step to analyse any kind of data. Rather than a specific set of procedures, EDA is an approach, or a philosophy, which seeks to explore the most important and often hidden patterns in a data set. In EDA, we explore the data and try to come up with a hypothesis about it which we can later test using hypothesis testing. Statisticians use it to take a bird's eye view of the data and try to make some sense of it. EDA usually follows a procedure of processes which are as follows:

(i) Data Sourcing - deals with Collection of data from different sources, primary or secondary.

(ii) Data cleaning are there are various types of quality issues when it comes to data, that's why data cleaning one of the most timeconsuming steps of data analysis.

(iii) Univariate analysis analysing variable one at a time.

(iv) Bivariate analysis analysing more than one variable at a time by grouping and filtering. (v) Derived matrix deriving data-driven, and objective driven Matrix for JEE main conclusions.

\section{Compound Growth Rate}

Compound function is given by the equation:

$$
Y_{t}=a b^{t} \text { or } \log Y_{t}=\log a+t \log b
$$

Where,

$\mathrm{t}$ is the time in months, independent variable

$Y_{t}$ is the characteristic

$\mathrm{a}$ and $\mathrm{b}$ are parameters

The parameters ' $a$ ' and ' $b$ ' are calculated by applying the method of Ordinary Least Squares (OLS). The compound growth rate (CGR \%) is calculated by using the formula:

$$
\text { CGR }(\%)=(b-1) \times 100
$$

Month-wise comparison for the volume of transaction for RTGS, NEFT, Debit card and Mobile payments were shown in Table 1 and depicted in Plot 1.

RTGS had an average of 8.63 million transactions before demonetization and after demonetization it was seen to have an average volume of 9.56 million which indicated an overall growth of 11percent (Table 1) in an average. RTGS observed CAGR of .20 and .60 percent before and after demonetization respectively (Table 3 ).

Transactions through NEFT were observed to have an average volume of 120.19 and 153.04 million before and after demonetisation respectively. The average growth observed was 27 percent. CGR for before and after demonetisation were 2.10 and -1.00 percent respectively.

Debit card payments had an average volume of 92.98 million before demonetisation whereas after demonetisation it was seen to have an average of 239.02 million indicating an overall growth of 157 percent in an average. CGR observed for debit card payments were -7.20 and -0.40 percent before and after demonetisation respectively.

Mobile payments observed a growth of 5 percent with an average of 69.14 million transactions before demonetisation and 72.55 million after demonetisation. CGR observed for mobile payments 
Table 1: Comparison Number of transactions before and after Demonetisation

\begin{tabular}{ccccccccc}
\hline & \multicolumn{3}{c}{ BEFORE Demonetisation (May-16 to Oct-16) (Million) } & \multicolumn{5}{c}{ AFTER Demonetisation (Up to Oct-17) (Million) } \\
\cline { 2 - 8 } & DEBIT & MOBILE & NEFT & RTGS & DEBIT & MOBILE & NEFT & RTGS \\
\hline Maximum & 121.26 & 78.11 & 133.21 & 9.00 & 310.99 & 116.67 & 186.7 & 12.53 \\
Minimum & 81.6 & 61.73 & 113.48 & 8.25 & 205.53 & 56.18 & 123.04 & 7.87 \\
Average & 92.98 & 69.14 & 120.19 & 8.63 & 239.02 & 72.55 & 153.04 & 9.56 \\
\hline Total & $\mathbf{5 5 7 . 9 2}$ & $\mathbf{4 1 4 . 8 7}$ & $\mathbf{7 2 1 . 1 9}$ & $\mathbf{5 1 . 8 1}$ & $\mathbf{2 8 6 8 . 3 5}$ & $\mathbf{8 7 0 . 6 8}$ & $\mathbf{1 8 3 6 . 5 7}$ & $\mathbf{1 1 4 . 8 1}$ \\
\hline
\end{tabular}

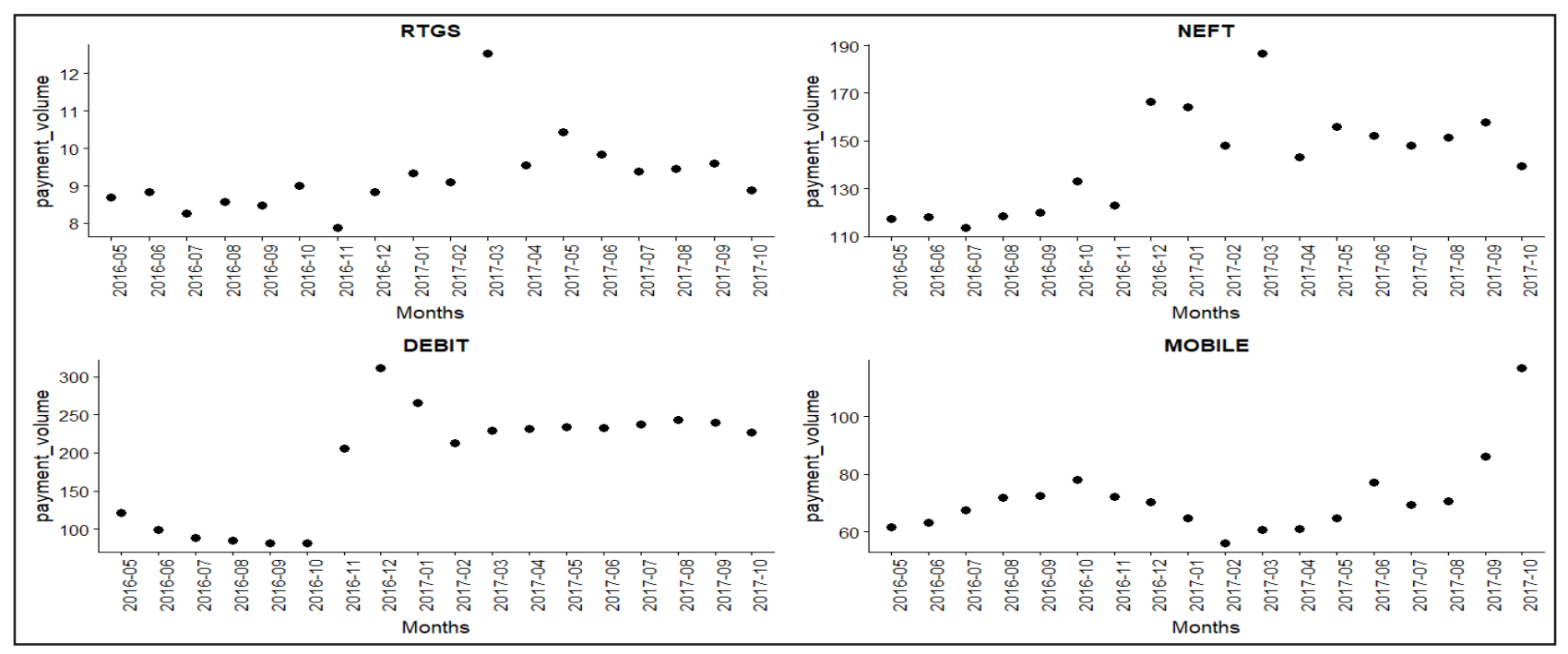

Plot 1: Month-wise pattern for volume of transactions (Millions)

were 4.90 and 3.40 percent before and after demonetisation respectively.

Table 2: Percentage growth of Number of transactions

\begin{tabular}{|c|c|c|c|c|}
\hline & DEBIT $(\%$ & MOBILE (\%) & NEFT (\%) & RTGS (\%) \\
\hline Average & 157 & 5 & 27 & 11 \\
\hline Total & 414 & 110 & 155 & 122 \\
\hline
\end{tabular}

Table 3: Compound Growth Rates of Volume for Before and After Demonetisation

\begin{tabular}{ccc}
\hline \multirow{2}{*}{ CGR } & \multicolumn{2}{c}{ Volume (\%) } \\
\cline { 2 - 3 } & Before & After \\
\hline RTGS & 0.20 & 0.60 \\
NEFT & 2.10 & -1.00 \\
DEBIT CARD & -7.20 & -0.40 \\
MOBILE & 4.90 & 3.40 \\
\hline
\end{tabular}

Month-wise comparison for the value of transactions through different modes of payment viz., RTGS, NEFT, Debit card and Mobile payments was made and shown in Table 4, 5, 6 and depicted in Plot 2.

Before demonetization, RTGS had an average value of 77482.7 billion rupees, which went up to an average value of 88953.36 billion rupees after demonetization with a growth of 15 percent in an average (Table 5). CGR of -1.80 and 1.00 percent were observed for RTGS before and after demonetization respectively (Table 6).

Transactions through NEFT were observed an average value of 8807.00 and 12233.11 billion before and after demonetisation respectively. The average growth observed was 39 percent. CGR for before and after demonetisation were 4.20 and 2.00 percent respectively.

Debit card payments had an average value of 293.05 billion before demonetisation whereas after demonetisation it had an average of 446.99 billion indicating an overall growth of 53 percent in an average. CGR observed for debit card payments were -15.60 and 1.10 percent before and after demonetisation respectively.

Mobile payments observed a growth of 46 percent with an average value of 887.02 billion of transactions before demonetisation and 1299.47 billion after demonetisation. CGR observed for mobile payments were 14.10 and -1.60 percent before and after demonetisation respectively. 
Table 4: Comparison of Value- Before and After Demonetisation

\begin{tabular}{ccccccccc}
\hline & \multicolumn{3}{c}{ BEFORE Demonetisation } & May-16 to Oct-16)(Billion) & \multicolumn{4}{c}{ AFTER Demonetisation (Up to Oct-17) (Billion) } \\
\cline { 2 - 8 } & DEBIT & MOBILE & NEFT & RTGS & DEBIT & MOBILE & NEFT & RTGS \\
\hline Max & 505.34 & 1139.4 & 9880.16 & 86687.35 & 522.23 & 1940.65 & 16294.5 & 123375.8 \\
Min & 203.92 & 618.13 & 7732.54 & 65533.86 & 352.35 & 1019.16 & 8807.83 & 74218.81 \\
Average & 293.05 & 887.02 & 8807 & 77482.77 & 446.99 & 1299.47 & 12233.11 & 88953.36 \\
\hline Total & $\mathbf{1 7 5 8 . 3}$ & $\mathbf{5 3 2 2 . 1 7}$ & $\mathbf{5 2 8 4 2 . 0 5}$ & $\mathbf{4 6 4 8 9 6 . 6}$ & $\mathbf{5 3 6 3 . 8 8}$ & $\mathbf{1 5 5 9 3 . 6 5}$ & $\mathbf{1 4 6 7 9 7 . 3}$ & $\mathbf{1 0 6 7 4 4 0}$ \\
\hline
\end{tabular}

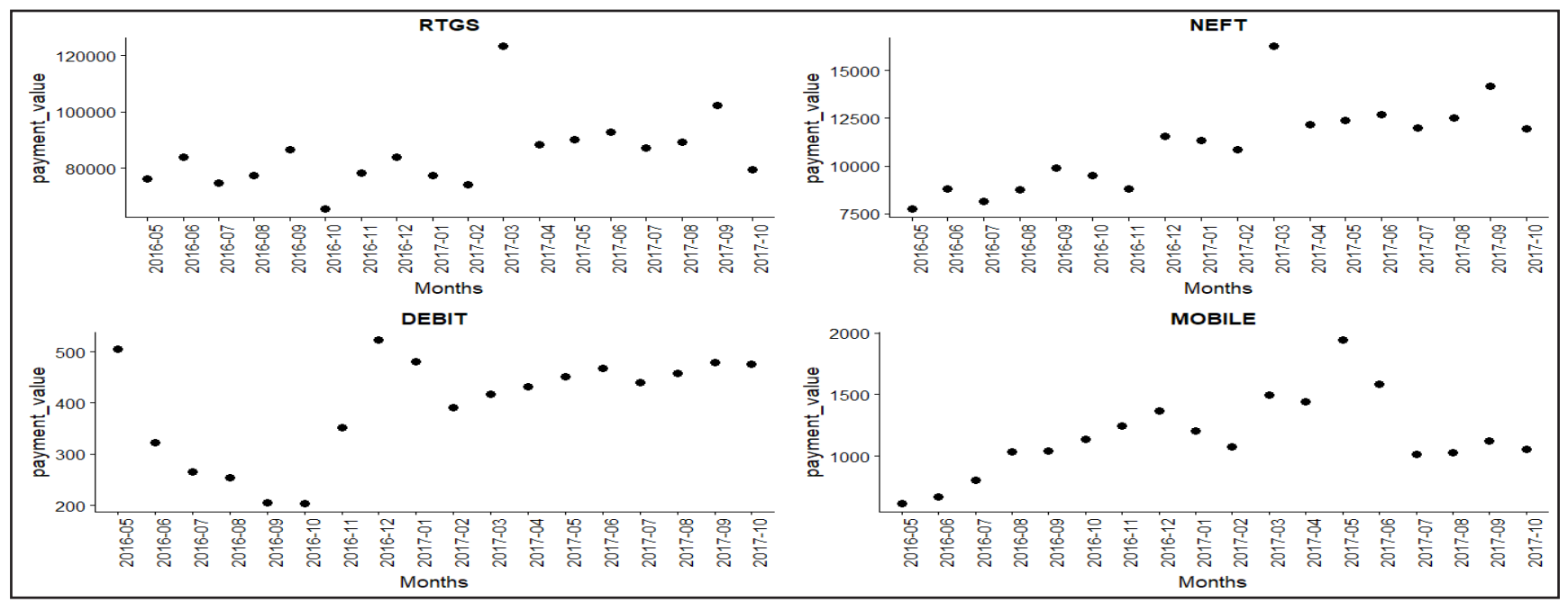

Plot 2: Month-wise pattern for value of transactions (Billions)

Comparison and exploration was made between volume and value of different modes of transactions considered in the study and the same was depicted in Plot 3.

Table 5: Percentage growth of value of transactions

\begin{tabular}{ccccc}
\hline & DEBIT(\%) & MOBILE(\%) & NEFT(\%) & RTGS(\%) \\
\hline Average & 53 & 46 & 39 & 15 \\
\hline Total & $\mathbf{2 0 5}$ & $\mathbf{1 9 3}$ & $\mathbf{1 7 8}$ & $\mathbf{1 3 0}$ \\
\hline
\end{tabular}

Table 6: Compound Growth Rates of Value for Before and After Demonetisation

\begin{tabular}{ccc}
\hline \multirow{2}{*}{ CGR } & \multicolumn{2}{c}{ Value (\%) } \\
\cline { 2 - 3 } & Before & After \\
\hline RTGS & -1.80 & 1.00 \\
NEFT & 4.20 & 2.00 \\
DEBIT CARD & -15.60 & 1.10 \\
MOBILE & 14.10 & -1.60 \\
\hline
\end{tabular}

RTGS found to have an inconsistent growth in the periods before and after demonetisation. It was observed that October-16 has lowest value of transactions and lowest with respect to volume was seen in the month of demonetisation November- 16 .
The highest value and volume of transaction were found in the month of March-17, it may be due to end of financial year. It was evident that demonetisation was found fruitful in case of RTGS as the value and volume increased when compared to before demonetisation.

NEFT, before demonetisation observed a good growth but in terms of volume and with an average base of 120 million users. Demonetisation increased its growth taking its base as higher as 165 million and the value of transaction was increased significantly with an average of 12000 billion Indian rupees.

Debit card usage as a payment mode was almost diminishing up to October-16 and it picked up well in the month of demonetisation and it continued to be same after November- 16 . The growth was very much significant for both value and volume of transactions making it highest used mode of payment after demonetisation.

Usage of Mobile payments were seen to increasing from last two years and it was found to affected adversely by demonetisation in terms of volume 

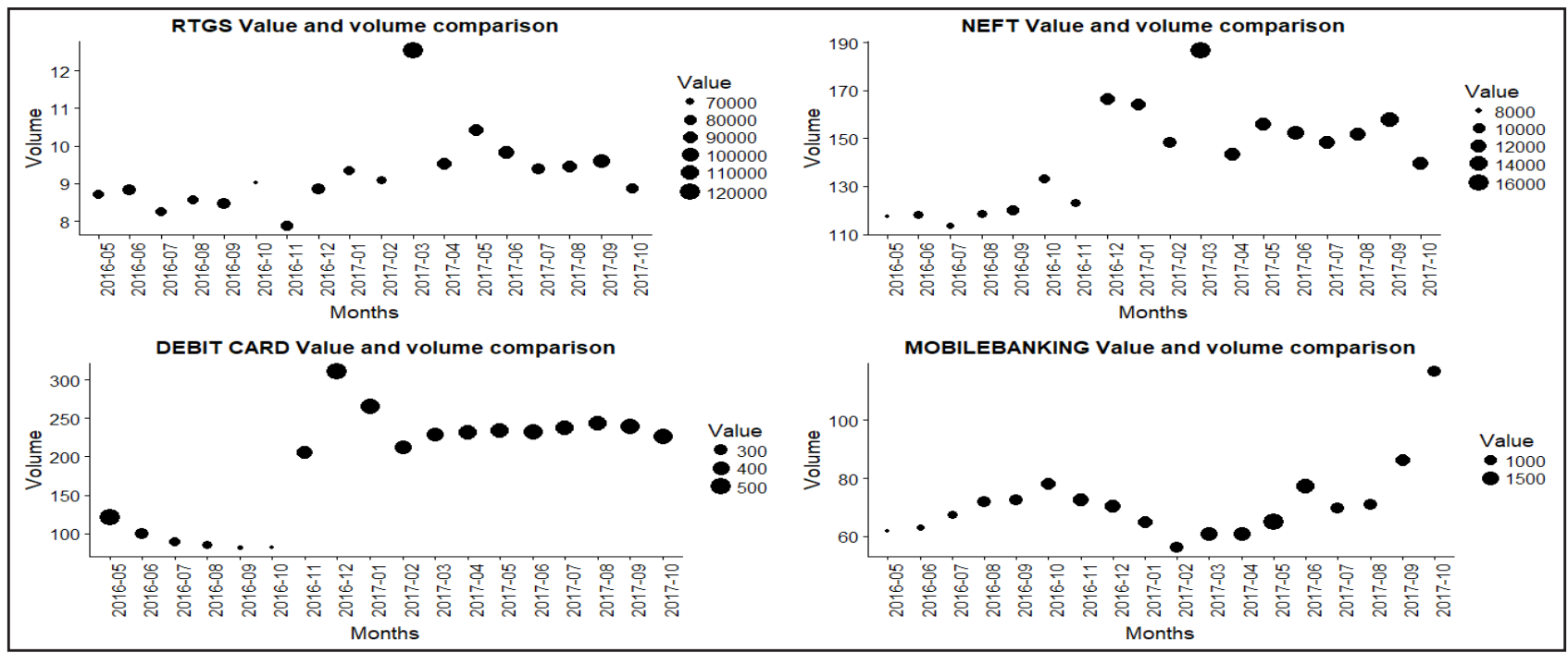

Plot 3: Month-wise Value (Billions) and Volume (Millions) comparison of different modes of transaction

initially and it picked up well after February-17. The point of notice here was, after February-17 Mobile payments had a growth in terms of volume but not in value, it may be because larger portion of people have been using this for day to day transactions were value is not more than 2000 Indian rupees.

\section{CONCLUSION}

Demonetization in India is a great effort taken by Indian government to combat with black money and corruption. Due to demonetization online transactions have been increased significantly which are more visible in RTGS and mobile transactions. So we may conclude that by increasing internet connectivity and bank branches to rural areas it can be increased further.

\section{REFERENCES}

http://www.india-briefing.com/news/growth-of-digitalpayments-systems-in-india-14797.html/

https://en.wikipedia.org/wiki/2016_Indian_banknote_ demonetisation

https:/www.mca.co.in/images/Demonetisation_MCA.PDF

http://www.dnaindia.com/business/report-digitaltransactions-surge-8085-after-demonetization-2558443

Pradeep H. Tawade, 2007. Future and Scope of Cashless Economy in India, IJARIIE, 2(3). 
